\title{
Reasons for discontinuation of GLPI receptor agonists: data from a real-world cross-sectional survey of physicians and their patients with type 2 diabetes
}

This article was published in the following Dove Press journal:

Diabetes, Metabolic Syndrome and Obesity:Targets and Therapy 29 September 2017

Number of times this article has been viewed

\section{Mirko V Sikirica' \\ Alan A Martin² \\ Robert Wood ${ }^{3}$ \\ Andrea Leith ${ }^{3}$ \\ James Piercy ${ }^{3}$ \\ Victoria Higgins ${ }^{3}$}

'Value Evidence and Outcomes, GlaxoSmithKline, Collegeville, PA, USA; ${ }^{2}$ Value Evidence and Outcomes, GlaxoSmithKline, London, UK; ${ }^{3}$ Diabetes, Adelphi Real World, Bollington, Cheshire, UK
Correspondence: Mirko V Sikirica Value Evidence and Outcomes, GlaxoSmithKline, I250 South Collegeville Road, Collegeville, PA 19426, USA

$\mathrm{Tel}+\mathrm{I} 6109172833$

Email mirko.x.sikirica@gsk.com
Aim: Nonadherence to glucagon-like peptide-1 receptor agonists (GLP1 RAs) is relatively common among patients with type 2 diabetes mellitus (T2DM). This study sought to identify reasons why patients discontinue GLP1 RAs.

Materials and methods: Retrospective data from the Adelphi Diabetes Disease Specific Programme were used. Physicians managing patients with T2DM were surveyed via face-to-face interviews, and patients treated for T2DM were surveyed via self-completed questionnaires. Patient data were stratified by current versus prior GLP1 RA use.

Results: Physicians ( $\mathrm{n}=443$ ) most frequently reported inadequate blood glucose control (45.6\%), nausea/vomiting (43.8\%), and gastrointestinal (GI) side effects (36.8\%) as reasons for GLP1 RA discontinuation. Patients ( $\mathrm{n}=194)$ reported the GI-related issues "Made me feel sick" (64.4\%) and "Made me throw up" (45.4\%) as their top reasons for discontinuation. The most common problems reported (excluding cost) for those currently using GLP1 RAs were "Prefer oral medication over injections" (patients 56\%, physicians 32.6\%), "Made me feel sick" (patients 38.1\%, physicians 16.3\%), and "Did not help lose weight" (patients $25.4 \%$, physicians $18 \%$ ). The most bothersome problems for patients globally (frequency reporting very/extremely bothersome) (excluding cost) were "Difficult to plan meals around" (55.6\%), "Made me throw up" (51.6\%), and "Caused weight gain" (50\%).

Conclusion: Both patients and physicians reported GI-related issues as a prominent factor, but disparities between patient experiences and physician perceptions were revealed, suggesting gaps in physician-patient communication. Understanding patients' expectations of GLP1 RAs and physicians' patient-management practices may help increase GLP1 RA adherence and thereby potentially enhance diabetes care.

Keywords: antidiabetic drug, cross-sectional survey, discontinuation, incretins, incretin therapy, glycemic control

\section{Introduction}

Diabetes is a highly prevalent condition, affecting $8.5 \%$ of the global population, requiring early diagnosis and treatment to increase the likelihood of favorable outcomes. ${ }^{1}$ Oral antidiabetic drugs (OADs), such as metformin, are first-line pharmacological agents for type 2 diabetes mellitus (T2DM). ${ }^{2}$ If OAD therapy fails to control blood glucose levels, patients with T2DM may be prescribed combination or add-on therapies, which can include injectable agents. Insulin is the most widely known injectable therapy; however, agents in a newer class, the glucagon-like peptide-1 receptor agonists (GLP1 RAs), 
may be prescribed instead. ${ }^{2}$ GLP1 RAs improve glycemic control by mimicking natural incretin hormones produced by the body, achieving efficacy without the risk of the hypoglycemia and weight gain that accompany insulin therapy. ${ }^{2-4}$

An ongoing challenge in T2DM treatment success is medication nonadherence. A study in six European countries showed significant discontinuation rates in the first year of GLP1 RA treatment. In that study, rates of persistence (continuation of the index therapy) at 180 days were $46.8 \%-73.5 \%$ among patients taking exenatide twice daily, $50.6 \%-80.1 \%$ with liraglutide once daily, and $57.5 \%-74.6 \%$ with exenatide once weekly. ${ }^{5}$ In a study in the US, less than half of patients with T2DM treated with exenatide or liraglutide had at least an $80 \%$ proportion of days covered (medications on hand each day) during a 6-month period. ${ }^{6}$

Understanding the reasons why patients do not persist on GLP1 RA therapies may help providers choose medications based on specific attributes, which could help patients remain on therapy. To this end, it is important to understand whether prescribing physicians are aware of the problems experienced by patients taking GLP1 RA medications, because a lack of awareness among managing physicians may contribute to poor adherence or discontinuation.

Our study used real-world cross-sectional survey data reported by both patients and physicians. The primary objective was to understand, rank, and compare reasons for discontinuation in patients with T2DM who had discontinued a GLP1 RA in the past 6 months. Additional objectives included describing specific problems with taking GLP1 RAs reported by patients and perceived by physicians, ranking and assessing how much these problems affected patients, and understanding whether physicians' perceptions reflected patients' experiences.

\section{Materials and methods}

Data used in this study originated from a retrospective analysis of the Adelphi Diabetes Disease Specific Programme $\left(\mathrm{DSP}^{\circledR}\right),{ }^{7}$ conducted from April through July 2014, in France, Germany, Italy, Spain, the UK (collectively referred to as EU5 countries), and the US. DSPs are large, multinational, crosssectional surveys conducted to provide impartial observations of real-world clinical practice from physicians and a sample of their own patients in specific therapy areas. These surveys have been implemented for several years and assessed for validity/representativeness. ${ }^{7-11}$ DSPs provide three sources of evidence: a physician interview, a physician-reported record form, and a patient self-completion questionnaire. Each of these sources is described herein. ${ }^{7}$
Physicians completed a face-to-face interview that explored perceptions of disease management, including those relating to problems experienced by patients treated with GLP1 RAs and how bothered they believed their patients were by these problems (Table S1)..$^{7-9,12}$ Subsequently, they provided information relating to patient demographics, patient management, current and previous antidiabetic therapy, and clinical attributes for their next 10 consecutive consulting patients with T2DM. To boost sample sizes where necessary, each physician recruited one additional patient with T2DM who had discontinued a GLP1 RA in the previous 6 months, and two additional patients receiving new drug classes, such as dipeptidyl peptidase-4 inhibitors, sodium/glucose cotransporter 2 inhibitors, and GLP1 RAs. These data were used when assessing the reasons for discontinuation of GLP1 RAs.

Patients were invited to complete a questionnaire (Table S1) independent of their physician, that included questions about demographics and their experiences and perceptions of T2DM treatment and management. Each patient provided consent for deidentified and aggregated reporting of research findings, and data were deidentified prior to receipt by the research team. Patient experiences were ascertained using questions about whether they had stopped GLP1 RA medication, and if so, their reasons for stopping. Patients who reported current treatment with a GLP1 RA were also asked questions about problems experienced using that specific injectable therapy and the degree of bother they experienced, using a 4-point scale: "not at all", "somewhat", "very", and "extremely" bothered.

To be eligible for inclusion in the overall survey, physicians were required to be responsible for treatment decisions and management of patients with T2DM, and patients were required to be $\geq 18$ years of age, have a physician-confirmed diagnosis of T2DM, and be treated with an antidiabetic medication (OAD/GLP1 RA/insulin). For inclusion in the current analysis, physicians were required to be practicing in the EU5 countries or the US, and patients were required to have received treatment with a GLP1 RA, as confirmed by his or her physician. Included patients were classified by whether their physician currently prescribed a GLP1 RA or had discontinued use within the period of 6 months prior to data collection. Patient-reported data were analyzed for those patients who said they were still taking GLP1 RA treatment and for those who stated that they had discontinued GLP1 RA in the previous 6 months.

The DSP survey was conducted in accordance with the European Pharmaceutical Market Research Association code of conduct for international health care market research ${ }^{13}$ and 
in full accordance with the US Health Insurance Portability and Accountability Act of $1996^{14}$ and its European equivalents; ${ }^{13,15}$ as such, ethical approval was not required. Informed consent was obtained after physicians explained the aims and nature of the research and patients reviewed the collection forms. Data were collected by local fieldwork partners and were fully anonymized. Physicians were reimbursed for their participation in the study by the local fieldwork partners at fair market rates, and the fieldwork teams adhered to national data collection regulations. A full description of the methodology has been published previously.?

\section{Statistical analysis}

Descriptive statistics were used for reporting the data: frequencies and percentages for categorical data, and means for numeric data. Descriptive statistics were ranked in descending order where applicable. Patients with missing values for a particular variable were removed from all analyses wherever the variable was used; however, these patients were still eligible for inclusion in other analyses where values were present. Data are presented either as global (all patients/physicians) or divided by region (participating EU5 countries vs the US). All analyses were performed in Stata version 13.0 or later.

\section{Results \\ Participants}

The survey included 10,987 patients $(8,091$ from the EU5 region and 2,896 from the US) recruited from 851 physicians, of whom 499 were primary care physicians (374 from the EU5 and 125 from the US) and 352 diabetologists/endocrinologists
(252 from the EU5 and 100 from the US). A total of 2,173 patients (1,462 from the EU5 and 711 from the US) were eligible for inclusion in the analysis (Figure 1). Some significant differences were observed in this convenience sample between the baseline characteristics of those who discontinued versus those who did not discontinue GLP1 RAs (Table 1 and Table S2), including differences in the most recent glycated hemoglobin $\left(\mathrm{HbA}_{1 \mathrm{c}}\right)$ results $(7.7 \%$ vs $7.9 \%)$. Patient characteristics between the EU5 and US regions are compared in Table 2 and Table S3 , and also show that some characteristics were significantly different between the two groups.

\section{Reasons for GLPI RA discontinuation}

Figure 2A shows that the reason for patient discontinuation of GLP1 RA most frequently reported by physicians was "Lack of blood glucose control" (45.6\%), followed by gastrointestinal (GI)-related reasons, ranked second (nausea/ vomiting [43.8\%]) and third (GI side effects [36.8\%]). GIrelated issues were the top two patient-reported reasons for GLP1 RA discontinuation in the past 6 months (Figure 2B), with "Made me feel sick" as the most frequently reported reason (64.4\%), followed by "Made me throw up" (45.4\%). Other frequent patient-reported reasons for discontinuing were "Prefer oral medication over injections" (39.7\%) and "Inadequate blood glucose control" (34.5\%).

\section{Experience with current GLPI RA usage}

Figure 3 shows each problem experienced with current GLP1 RA usage ranked by the frequency with which patients reported it compared side by side with the mean

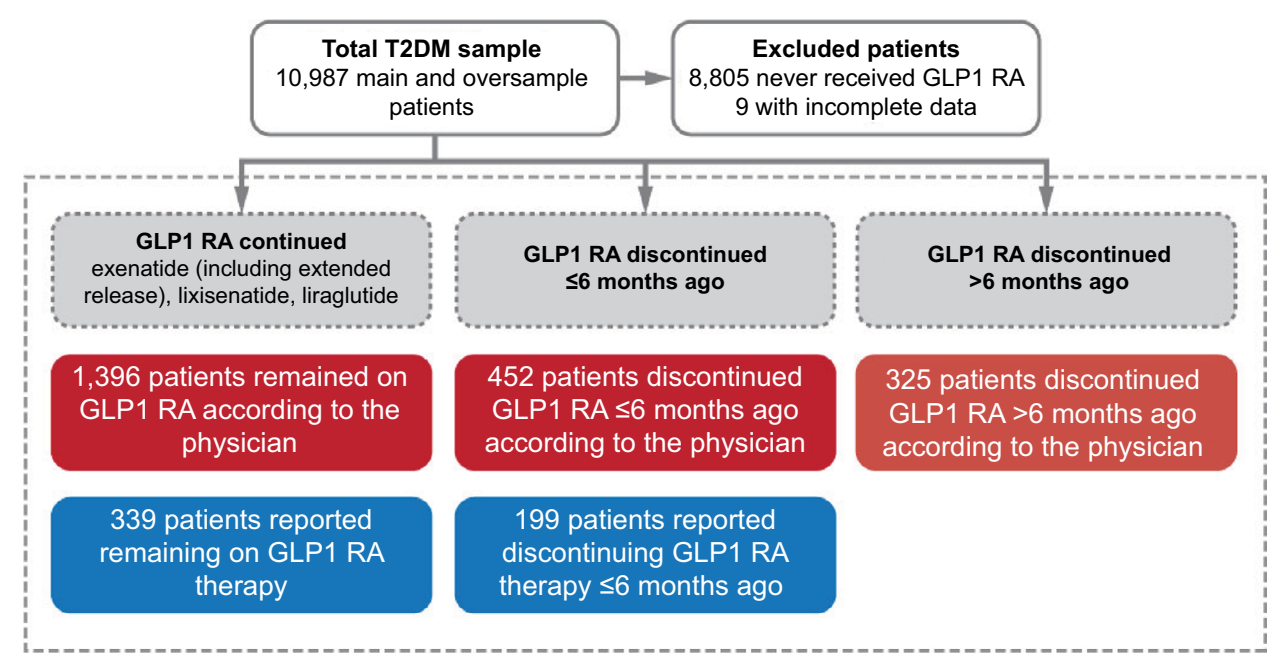

Figure I Patient-survey cohort $(n=2,173)$.

Notes: Bases for each analysis differ based on the number of responses for question.

Abbreviations: GLPI RA, glucagon-like peptide-I receptor agonist; T2DM, type 2 diabetes mellitus. 
Table I Patient demographics and clinical characteristics by GLPI RA status (global)

\begin{tabular}{|c|c|c|c|c|c|}
\hline Characteristic & $\begin{array}{l}\text { Overall } \\
\text { sample } \\
(n=2,173)\end{array}$ & $\begin{array}{l}\text { Remain on } \\
\text { GLPI RA } \\
(n=1,396)\end{array}$ & $\begin{array}{l}\text { Discontinued } \\
\leq 6 \text { months } \\
\text { prior }(n=452)\end{array}$ & $\begin{array}{l}\text { Discontinued } \\
>6 \text { months } \\
\text { prior }(n=325)\end{array}$ & $P$-value \\
\hline \multicolumn{6}{|l|}{$\overline{\text { Age }}$} \\
\hline Mean years (SD) & $57.2(10.4)$ & $57.2(10.3)$ & $57.3(9.9)$ & $57($ (II.3) & $0.9122(\mathrm{KW})$ \\
\hline \multicolumn{6}{|l|}{ Sex } \\
\hline Male, n (\%) & $\mathrm{I}, \mathrm{I} 83(54.5)$ & $748(53.6)$ & $265(58.8)$ & $170(52.3)$ & $0.1107\left(\chi^{2}\right)$ \\
\hline \multicolumn{6}{|l|}{ Body mass index } \\
\hline Mean kg/m² (SD) & $33.5(6.5)$ & $33.6(6.5)$ & $32.9(6.4)$ & $33.8(7)$ & $0.1653(\mathrm{KW})$ \\
\hline \multicolumn{6}{|l|}{ Most recent $\mathrm{HbA}$, result } \\
\hline Mean percentage (SD) & $7.7(\mathrm{I} .3)$ & $7.7(1.3)$ & $7.9(1.3)$ & $7.9(1.5)$ & $<0.000 \mathrm{I}(\mathrm{KW})$ \\
\hline$<7, \mathrm{n}(\%)$ & $626(29.2)$ & $440(31.8)$ & $102(22.8)$ & $84(26.5)$ & $0.0007\left(\chi^{2}\right)$ \\
\hline \multicolumn{6}{|l|}{ Disease duration } \\
\hline Mean weeks (SD) & $316.4(274.5)$ & $311.8(275.4)$ & $308.5(254.5)$ & $350.9(299.9)$ & $0.1915(\mathrm{KW})$ \\
\hline \multicolumn{6}{|l|}{ Concomitant conditions, $n$ (\%) } \\
\hline None & $324(14.9)$ & $202(14.5)$ & $74(16.4)$ & $48(14.8)$ & $0.6128\left(\chi^{2}\right)$ \\
\hline \multicolumn{6}{|l|}{ Cardiovascular } \\
\hline Atherosclerosis & $|4|(6.5)$ & $90(6.4)$ & $20(4.4)$ & $31(9.5)$ & $0.0169\left(\chi^{2}\right)$ \\
\hline Coronary heart disease/artery disease & $184(8.5)$ & $111(8)$ & $52(11.5)$ & $21(6.5)$ & $0.0230\left(\chi^{2}\right)$ \\
\hline Heart failure & $54(2.5)$ & $33(2.4)$ & $15(3.3)$ & $6(1.8)$ & $0.3814\left(\chi^{2}\right)$ \\
\hline Hypertension & $1,398(64.3)$ & $914(65.5)$ & $291(64.4)$ & $193(59.4)$ & $0.1189\left(\chi^{2}\right)$ \\
\hline Stable angina & $46(2.1)$ & $30(2.1)$ & II (2.4) & $5(1.5)$ & $0.6871\left(\chi^{2}\right)$ \\
\hline \multicolumn{6}{|l|}{ Microvascular/ophthalmologic } \\
\hline Neuropathy (any) & $162(7.5)$ & $103(7.4)$ & $33(7.3)$ & $26(8)$ & $0.9197\left(\chi^{2}\right)$ \\
\hline Retinopathy (any) & $144(6.6)$ & $91(6.5)$ & $30(6.6)$ & $23(7.1)$ & $0.9357\left(\chi^{2}\right)$ \\
\hline \multicolumn{6}{|l|}{ Renal } \\
\hline Renal impairment & $106(4.9)$ & $58(4.2)$ & $21(4.6)$ & $27(8.3)$ & $0.0072\left(\chi^{2}\right)$ \\
\hline Urinary tract infection & $45(2.1)$ & $27(1.9)$ & $15(3.3)$ & $3(0.9)$ & $0.0576\left(\chi^{2}\right)$ \\
\hline \multicolumn{6}{|l|}{ Hepatic } \\
\hline Liver disease & $42(1.9)$ & $27(1.9)$ & $9(2)$ & $6(1.8)$ & $0.9896\left(\chi^{2}\right)$ \\
\hline Nonalcoholic steatohepatitis & $94(4.3)$ & $54(3.9)$ & $26(5.8)$ & $14(4.3)$ & $0.2312\left(\chi^{2}\right)$ \\
\hline
\end{tabular}

Abbreviations: GLPI RA, glucagon-like peptide-I receptor agonist; $\mathrm{HbA}_{\mathrm{lc}}$, glycated hemoglobin; KW, Kruskal-Wallis; SD, standard deviation.

physician-estimated frequency of the same problems. Figure 3A shows each problem ranked for both regions combined, whereas Figure $3 \mathrm{~B}$ and $3 \mathrm{C}$ show rankings for the EU5 and the US, respectively. For the global study population and all GLP1 RA usage problems, the percentage of patients who reported they experienced the problem was higher than the mean physicians' estimate. This was also true in the EU5 and the US for the most frequently reported issues. However, in a few exceptions in the US for less frequent problems, physician estimates were similar or slightly higher compared to patient reports of those problems (Figure 3C). Globally, "Prefer oral medication over injections" was reported as the most common issue with GLP1 RAs by both patients (56\%) and physicians (32.6\%). The second most frequently patient-reported clinical problem was "Made me feel sick" (38.1\%), followed by concern about lack of weight loss ("Did not help lose weight" [25.4\%]), whereas physicians estimated these problems in the reversed order of frequency ( $18 \%$ weight vs $16.3 \%$ sickness). The cost of medication played an important role globally, with $26.9 \%$ of patients suggesting their medication was too costly, although this was mostly a factor in the US (48.6\% in the US vs $9.5 \%$ in the EU5). Other patient-reported issues that differed in frequency between the EU5 and the US were "Injections were painful" (EU5 14\%, US 25\%) and "Regular injections too inconvenient" (EU5 26.3\%, US 9\%).

\section{Effect of problems on the patient}

Figure 3D presents the number of patients who reported being very or extremely bothered by each problem. When experienced, the most bothersome problems (excluding cost) were "Difficult to plan meals around" (55.6\%), "Made me throw up" (51.6\%), and "Caused weight gain" (50\%). The first and second most prevalent patient-reported problems, "Prefer oral medication over injections" and "Made me feel sick", were very/extremely bothersome to a third and quarter of patients, respectively.

\section{Discussion}

This analysis used an established physician and patient survey methodology to evaluate real-world issues with 
Table 2 Patient demographics and clinical characteristics by region

\begin{tabular}{|c|c|c|c|}
\hline Characteristic & EU5 $(n=1,462)$ & US $(n=7 I I)$ & $P$-value \\
\hline \multicolumn{4}{|l|}{$\overline{\text { Age }}$} \\
\hline Mean years (SD) & $58.5(9.8)$ & $54.4(10.9)$ & $<0.000 \mathrm{I}(\mathrm{MW})$ \\
\hline \multicolumn{4}{|l|}{ Sex } \\
\hline Male, n (\%) & $817(55.9)$ & $366(5 \mathrm{I} .5)$ & $0.0539(\mathrm{FE})$ \\
\hline \multicolumn{4}{|l|}{ Body mass index } \\
\hline Mean kg/m² (SD) & $33(6.3)$ & $34.5(6.9)$ & $<0.000 \mathrm{I}(\mathrm{MW})$ \\
\hline \multicolumn{4}{|l|}{ Most recent $\mathrm{HbA}_{\mathrm{Ic}}$ result } \\
\hline Mean percentage (SD) & $7.8(1.3)$ & $7.7(1.4)$ & $0.292(\mathrm{MW})$ \\
\hline$<7, \mathrm{n}(\%)$ & $420(29.1)$ & $206(29.4)$ & $0.8794(\mathrm{FE})$ \\
\hline \multicolumn{4}{|l|}{ Disease duration } \\
\hline Mean weeks (SD) & $34 I .9(28 I .1)$ & $245.1(241.6)$ & $<0.000 \mathrm{I}(\mathrm{MW})$ \\
\hline \multicolumn{4}{|l|}{ Concomitant conditions, $\mathrm{n}(\%)$} \\
\hline None & $259(17.7)$ & $65(9.1)$ & $<0.000 ।(\mathrm{FE})$ \\
\hline \multicolumn{4}{|l|}{ Cardiovascular } \\
\hline Atherosclerosis & $93(6.4)$ & $48(6.8)$ & 0.7117 (FE) \\
\hline Coronary heart disease/artery disease & $124(8.5)$ & $60(8.4)$ & $\mathrm{I}(\mathrm{FE})$ \\
\hline Heart failure & $42(2.9)$ & $12(1.7)$ & 0.1069 (FE) \\
\hline Hypertension & $920(62.9)$ & $478(67.2)$ & $0.0505(\mathrm{FE})$ \\
\hline Stable angina & $38(2.6)$ & $8(I . I)$ & 0.0257 (FE) \\
\hline \multicolumn{4}{|l|}{ Microvascular/ophthalmologic } \\
\hline Neuropathy (any) & $87(6)$ & $75(10.5)$ & 0.0002 (FE) \\
\hline Retinopathy (any) & $120(8.2)$ & $24(3.4)$ & $<0.000 ।(\mathrm{FE})$ \\
\hline \multicolumn{4}{|l|}{ Renal } \\
\hline Renal impairment & $70(4.8)$ & $36(5.1)$ & $0.832(\mathrm{FE})$ \\
\hline Urinary tract infection & $30(2.1)$ & $15(2.1)$ & $\mathrm{I}(\mathrm{FE})$ \\
\hline \multicolumn{4}{|l|}{ Hepatic } \\
\hline Liver disease & $32(2.2)$ & $10(1.4)$ & $0.2474(\mathrm{FE})$ \\
\hline Nonalcoholic steatohepatitis & $69(4.7)$ & $25(3.5)$ & $0.2172(\mathrm{FE})$ \\
\hline
\end{tabular}

Abbreviations: EU5, France, Germany, Italy, Spain, the UK; FE, Fisher's exact; MW, Mann-Whitney (U); HbA lc glycated hemoglobin.

GLP1 RA medications, including reasons for discontinuation, problems experienced with continuing GLP1 RA treatment, and the effect of these problems on patients. In addition, we examined to what extent physicians' perceptions reflected patient experience. During the analysis, several key themes emerged.

First, there was a disparity between patient-reported frequency of particular problems and physicians' perceptions of how frequently these problems occurred. Our results demonstrated a generally higher magnitude of reporting of problems or burdens by patients when compared with the physicians' perceptions overall. Among both patients and physicians, "Prefer oral medication over injections" was the most common issue with GLP1 RAs, although this concern was reported by $56 \%$ of patients and only $33 \%$ of physicians (Figure 3A). From this point, the rankings of the issues diverged, with the next patient-reported problem being "Made me feel sick", whereas physicians perceived the next most prominent issue to be "Did not help lose weight". It is possible that physicians placing higher priority on weight loss could result in underrecognition of GI issues, because whereas weight loss is measurable and therefore easily noted at checkup appointments, GI issues may go undetected unless specifically mentioned by the patient or queried by the physician. This links with another theme that emerged: the preponderance of GI-related issues. GI side effects are commonly experienced by patients treated with medications for T2DM and have been identified as a likely contributor to nonadherence. ${ }^{16-19}$ This study suggests that this is the case for GLP1 RA users, as we found GI issues were three of the top five reasons for GLP1 RA discontinuation for patients across both geographic regions, indicating that patients may place more importance on factors that interrupt daily routines and feelings of well-being than efficacy. Although physicians did not rank GI issues as highly as patients, physicians do clearly consider GI issues to be one of the major contributors to GLP1 RA discontinuation.

Although clinical trials have demonstrated that GLP1 RAs are effective at reducing $\mathrm{HbA}_{1 \mathrm{c}}$ levels, these trials have also highlighted the differences in the type, frequency, and severity of adverse events (AEs) compared to insulin and among drugs within the GLP1 RA class..$^{20,21}$ Our results suggest the outcomes of these trials may not be informing the interactions of prescribing physicians with patients in 


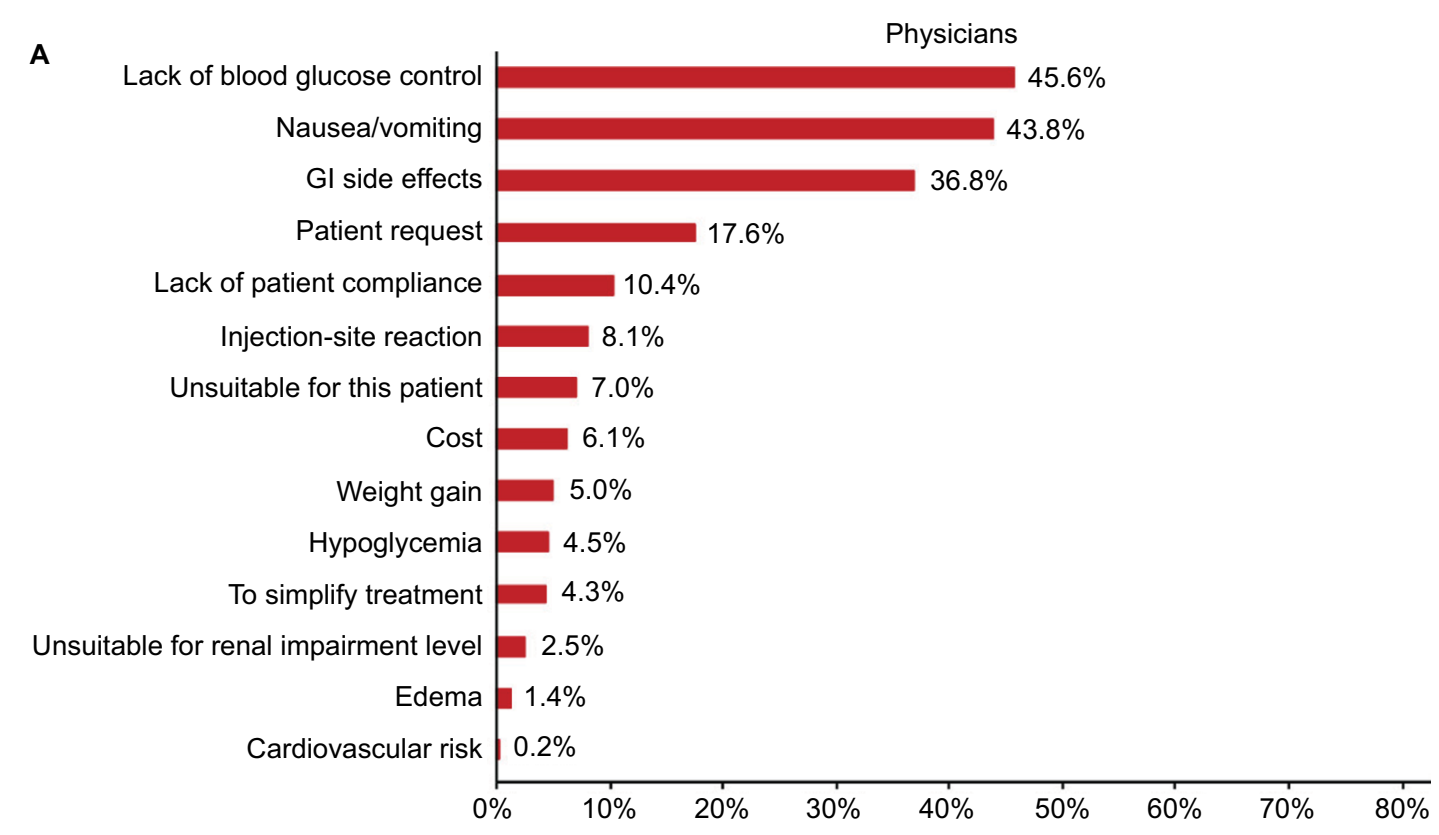

$$
\text { B }
$$

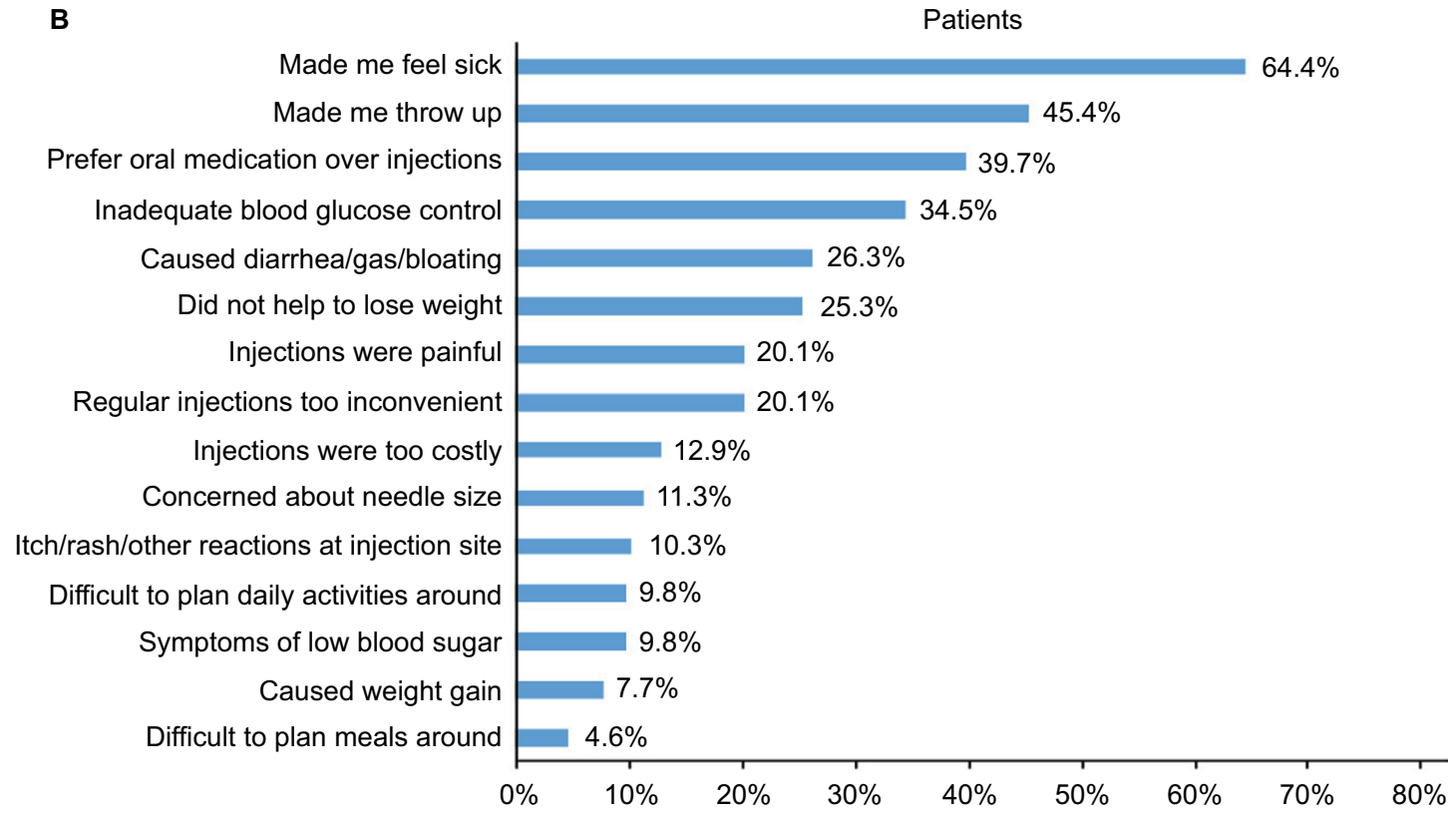

Figure 2 Reasons for GLPI RA discontinuation in the past 6 months, ranked by frequency.

Notes: (A) Physicians ( $n=443)$; (B) patients $(n=194)$.

Abbreviations: GI, gastrointestinal; GLPI RA, glucagon-like peptide-I receptor agonist.

their real-world practices. In our analysis, the proportion of patients reporting problems encountered while taking GLP1 RA therapy were two to three times higher than physicians' estimates. While both physicians and patients report a preference for OADs over injections as the most prevalent issue with using GLP1 RAs, patients placed greater emphasis than physicians on such problems as feeling sick, lack of weight loss, and the cost of injectable medications. Regarding the latter issue, there was considerable disparity between the US and EU5 when comparing the patient versus physician perspectives on the cost of injectables; however, this is likely explained by disparities in how health care is funded and administered between those regions.

Data used for this analysis are more likely to provide a representative, real-world sample of patients with T2DM and real-world patient behavior than randomized clinical trial data. ${ }^{10,22}$ For example, in clinical trials, $<5 \%$ of patients discontinued a GLP1 RA due to GI effects; however, higher rates, between $5 \%$ and $10 \%$, have been observed in clinical practice. ${ }^{23,24}$ Clinical trials have reported the most common 
A

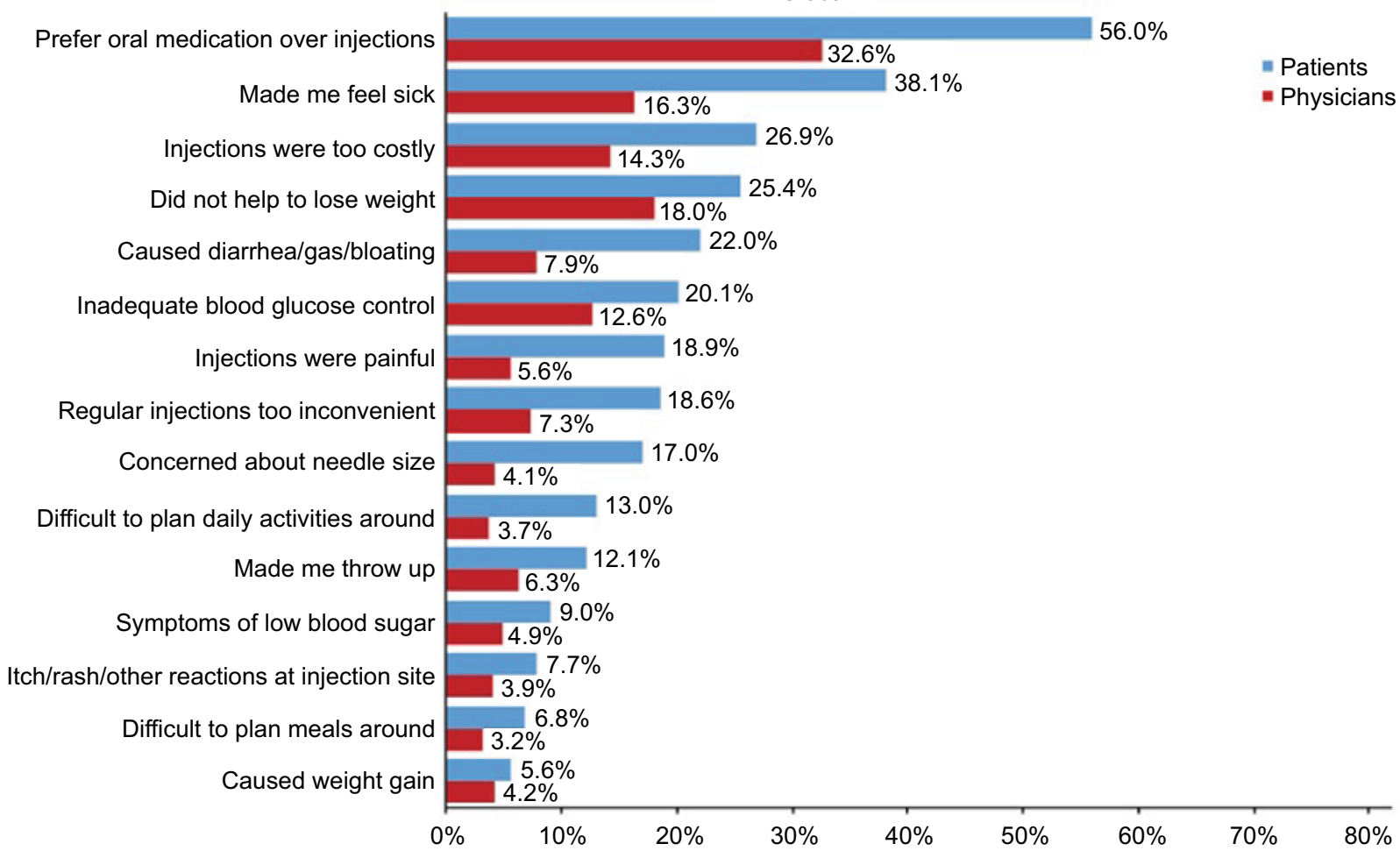

B

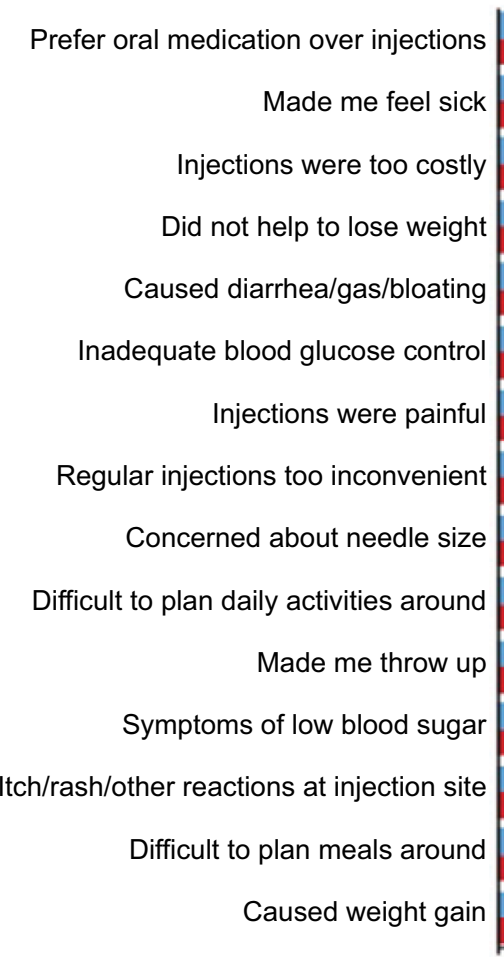

EU5

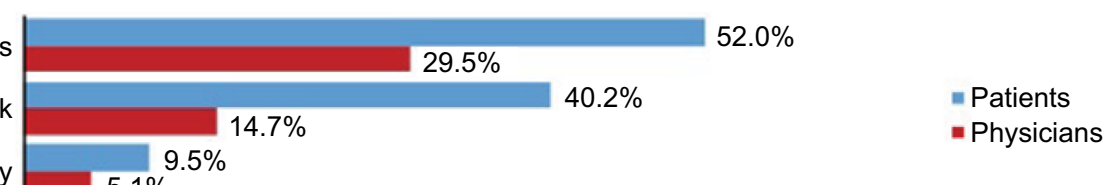


C

$$
\begin{array}{r}
\text { Prefer oral medication over injections } \\
\text { Made me feel sick } \\
\text { Injections were too costly } \\
\text { Did not help to lose weight } \\
\text { Caused diarrhea/gas/bloating } \\
\text { Inadequate blood glucose control } \\
\text { Injections were painful } \\
\text { Regular injections too inconvenient } \\
\text { Concerned about needle size } \\
\text { Difficult to plan daily activities around } \\
\text { Made me throw up } \\
\text { Symptoms of low blood sugar } \\
\text { Itch/rash/other reactions at injection site } \\
\text { Difficult to plan meals around } \\
\text { Caused weight gain }
\end{array}
$$

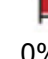

D

Global results: proportion of patients reporting problems as very or extremely bothersome

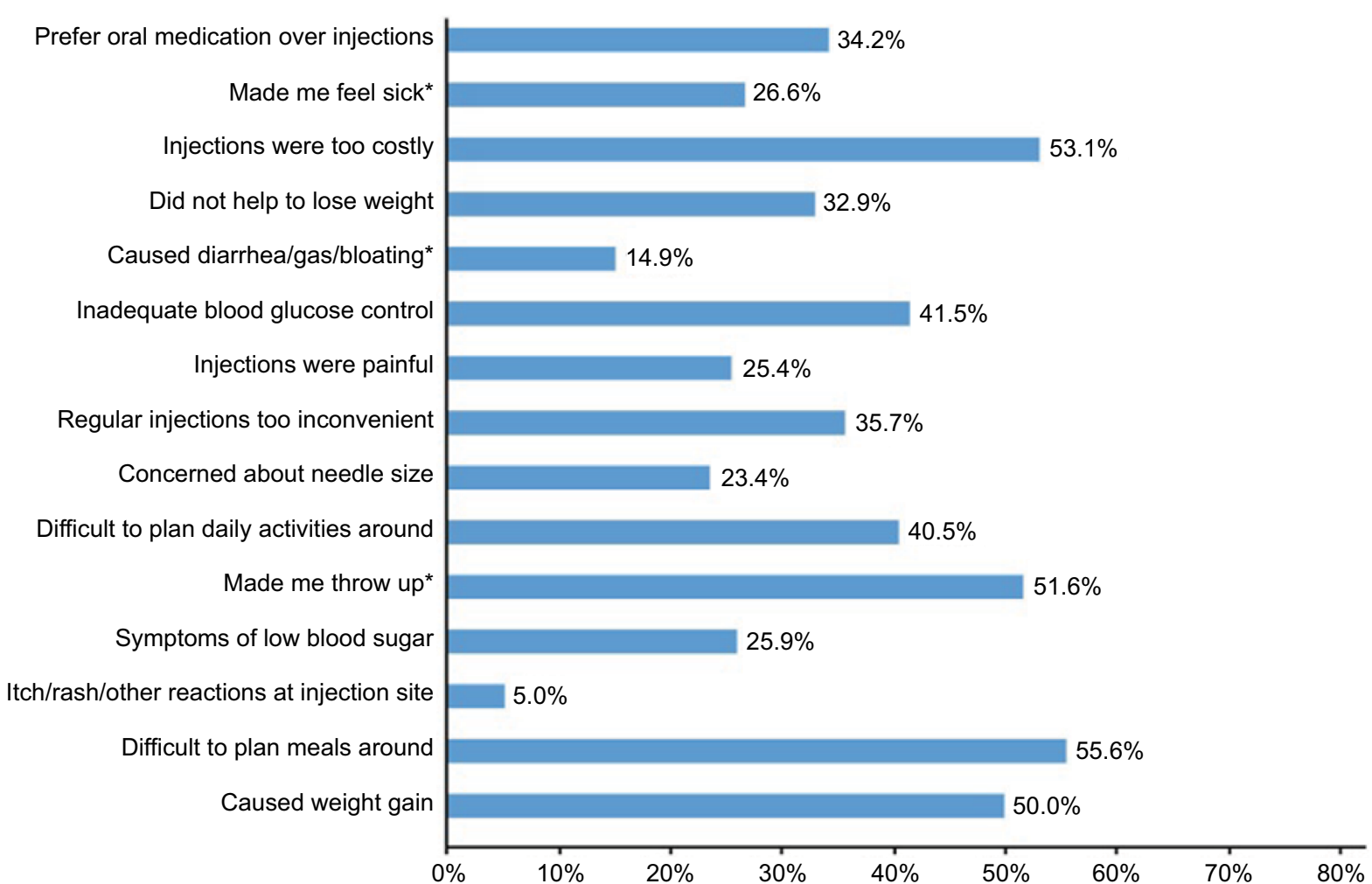

Figure 3 Problems reported with GLPI RA treatment.

Notes: *Gl-related issues. Physician-estimated versus patient-reported prevalence of each problem among patients currently using GLPI RAs. (A) Global results; (B) EU5 results (France, Germany, Italy, Spain, and the UK); (C) US results; (D) global results, proportion of patients reporting problems as very or extremely bothersome. Exact questions listed in Table SI.

Abbreviations: GI, gastrointestinal; GLPI RA, glucagon-like peptide-I receptor agonist.
US

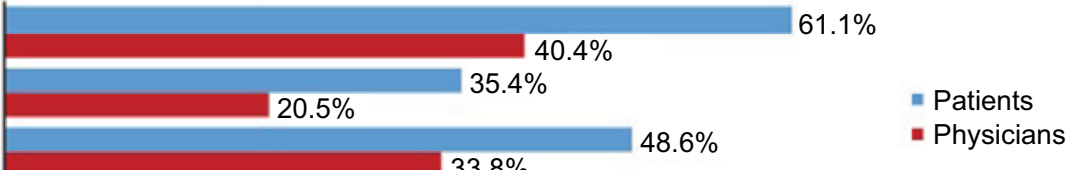

$9.0 \%$

$16.7 \%$

\begin{tabular}{l}
$6.9 \%$ \\
$6.5 \%$ \\
\hline
\end{tabular}

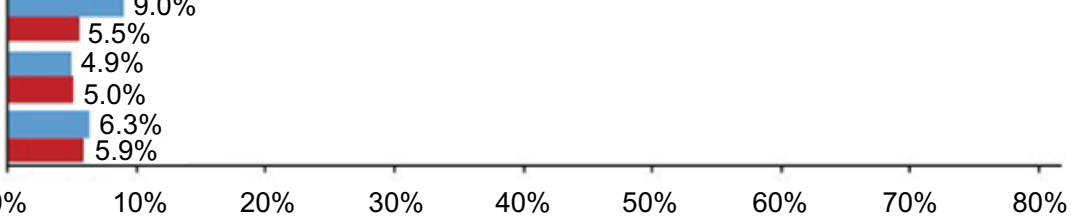


AEs with GLP1 RAs to be GI events, including diarrhea, nausea, and vomiting. ${ }^{25}$ Given time, these common AEs usually subside. ${ }^{23}$ However, a recent evaluation of the validity of randomized clinical trials that included patients with T2DM suggested that only approximately half of the actual number ${ }^{26}$ of patients with diabetes in the general population were represented by such studies. Additionally, up to $90 \%$ of patients with T2DM screened did not qualify for trials, and $49 \%$ of patients with newly diagnosed T2DM were found to be ineligible. ${ }^{26}$ This finding underscores the importance of obtaining and using real-world data when possible, while remaining cautious when applying clinical trial findings to the population at large.

Our study had several limitations. First, the analysis samples drawn from the DSP database represented a convenience sample of consulting patients with T2DM who used and/or discontinued a GLP1 RA, and the subgroup of patients who had discontinued a GLP1 RA in the past 6 months was relatively small. Therefore, it may not truly represent the overall population of patients with T2DM; however, the methodology did aim to eliminate possible selection bias by removing direct influence from the physician on the selection process. Additionally, while minimal exclusion criteria governed the selection of physicians, physician inclusion was likely influenced by the selection process, willingness to take part, and practical considerations of geographical location. Finally, the quality of data depended, to a large extent, on the accurate reporting of information by physicians and patients, which could have been subject to recall bias by those patients who were recalling a 6-month discontinuation period.

In conclusion, this research helps to address the question of why patients discontinue their GLP1 RA medication. One issue identified was a disparity between patient-reported experiences and physician perceptions and the effect of that disparity on treatment persistence and adherence. Examining the reasons for the disparity may help to identify some issues that are not being discussed and addressed with patients. Specifically, GI-related issues were confirmed as a prominent factor in the experience of both patients treated with GLP1 RAs and their physicians. There was a general trend for a similar disparity between patient reporting and physician perception in the EU5 compared with the US; however, not all disparities were the same. Understanding patient and physician interactions may help to improve medication choice and result in more patients remaining on GLP1 RA therapy. These findings are novel in highlighting a gap in physician and patient communication and understanding when administering GLP1 RA therapy and when recognizing, managing, and experiencing its AEs. Understanding patients' expectations of GLP1 RAs and physicians' patient management practices may help increase GLP1 RA adherence and thereby potentially enhance diabetes care overall.

\section{Author contributions}

All authors meet the criteria set forth by the International Committee of Medical Journal Editors. MVS, AAM, RW, AL, JP, and VH made substantial contributions to the conception and design of the study, revised the article for important intellectual content, and approved the final version to be published. All authors agree to be accountable for all aspects of the work.

\section{Acknowledgments}

The authors would like to thank the study participants. The authors also thank Nate Connors, PhD (NucleusX, Hamilton, NJ, USA) for writing assistance, and Catherine Martin (MediTechMedia, Hamilton, NJ, USA) and Prachi Patil, MSc (AOIC, LP, Exton, PA, USA) for editorial assistance. The study was funded by GlaxoSmithKline.

\section{Disclosure}

MVS and AAM are employees and shareholders of GlaxoSmithKline (GSK) in Collegeville, PA, USA, and Uxbridge, $\mathrm{UK}$, respectively. RW, AL, JP, and $\mathrm{VH}$ are employees of Adelphi Real World, Bollington, Cheshire, UK, which received funding from GSK related to this study.

\section{References}

1. World Health Organization. Global Report on Diabetes. 2016. Geneva: WHO; 2016.

2. American Diabetes Association. Approaches to glycemic treatment Diabetes Care. 2016;39(Suppl 1):S52-S59.

3. Davidson JA. Incretin-based therapies: focus on effects beyond glycemic control alone. Diabetes Ther. 2013;4(2):221-238.

4. Fabunmi R, Nielsen LL, Quimbo R, et al. Patient characteristics, drug adherence patterns, and hypoglycemia costs for patients with type 2 diabetes mellitus newly initiated on exenatide or insulin glargine. Curr Med Res Opin. 2009;25(3):777-786.

5. Divino V, DeKoven M, Hallinan S, et al. Glucagon-like peptide-1 receptor agonist treatment patterns among type 2 diabetes patients in six European countries. Diabetes Ther. 2014;5(2):499-520.

6. Johnston SS, Nguyen H, Felber E, et al. Retrospective study of adherence to glucagon-like peptide-1 receptor agonist therapy in patients with type 2 diabetes mellitus in the United States. Adv Ther. 2014;31(11):1119-1133.

7. Anderson P, Benford M, Harris N, Karavali M, Piercy J. Realworld physician and patient behaviour across countries: diseasespecific programmes - a means to understand. Curr Med Res Opin. 2008;24(11):3063-3072.

8. Wood R, Paoli CJ, Hays RD, Taylor-Stokes G, Piercy J, Gitlin M. Evaluation of the consumer assessment of healthcare providers and systems in-center hemodialysis survey. Clin J Am Soc Nephrol. 2014;9(6):1099-1108. 
9. Rodriguez MR, Small M, Fermer S, Bailey J, Wood R, Fink-Wagner AH. Real world burden of COPD: employed vs not in paid employment patients. J Health Prod. 2013;7(1):29-44.

10. Babineaux SM, Curtis B, Holbrook T, Milligan G, Piercy J. Evidence for validity of a national physician and patient-reported, cross-sectional survey in China and UK: the Disease Specific Programme. BMJ Open. 2016;6(8):e010352.

11. Higgins V, Piercy J, Roughley A, et al. Trends in medication use in patients with type 2 diabetes mellitus: a long-term view of real-world treatment between 2000 and 2015. Diabetes Metab Syndr Obes. 2016;9:371-380.

12. Atun RA, Lennox-Chhugani N, Drobniewski F, Samyshkin YA, Coker RJ. A framework and toolkit for capturing the communicable disease programmes within health systems: tuberculosis control as an illustrative example. Eur J Public Health. 2004;14(3):267-273.

13. European Pharmaceutical Market Research Association. Code of Conduct. Available from: http://www.ephmra.org/code-of-conduct/157/. Accessed January 18, 2017.

14. Department of Health and Human Services. Summary of the HIPAA privacy rule. 2016. Available from: https://www.hhs.gov/hipaa/for-professionals/ privacy/laws-regulations/index.html. Accessed January 18, 2017.

15. Market Research Society. The Data Protection Act 1998 and market research: guidance for MRS members. 2003. Available from: https:// www.mrs.org.uk/pdf/The $\% 20$ Data $\% 20$ Protection $\% 20$ Act $\% 20$ 1998\%20and\%20Market\%20Research.pdf. Accessed January 18, 2017.

16. Donnelly LA, Morris AD, Pearson ER. Adherence in patients transferred from immediate release metformin to a sustained release formulation: a population-based study. Diabetes Obes Metab. 2009;11(4):338-342.

17. Florez H, Luo J, Castillo-Florez S, et al. Impact of metformin-induced gastrointestinal symptoms on quality of life and adherence in patients with type 2 diabetes. Postgrad Med. 2010;122(2):112-120.
18. Sanyal D, Majumdar A. Low dose liraglutide in Indian patients with type 2 diabetes in the real world setting. Indian J Endocrinol Metab. 2013;17(Suppl 1):S301-S303.

19. Seufert J, Gallwitz B. The extra-pancreatic effects of GLP-1 receptor agonists: a focus on the cardiovascular, gastrointestinal and central nervous systems. Diabetes Obes Metab. 2014;16(8):673-688.

20. Trujillo JM, Nuffer W, Ellis SL. GLP-1 receptor agonists: a review of head-to-head clinical studies. Ther Adv Endocrinol Metab. 2015;6(1):19-28.

21. Porcellati F, Lucidi P, Bolli GB, Fanelli CG. GLP-1 RAs as compared to prandial insulin after failure of basal insulin in type 2 diabetes: lessons from the 4B and Get-Goal DUO 2 trials. Diabetes Metab. 2015;41(6 Suppl 1): 6S16-6S20.

22. Elliott L, Fidler C, Ditchfield A, Stissing T. Hypoglycemia event rates: a comparison between real-world data and randomized controlled trial populations in insulin-treated diabetes. Diabetes Ther. 2016;7(1):45-60.

23. Cefalu WT, Buse JB, Del Prato S, et al. Beyond metformin: safety considerations in the decision-making process for selecting a second medication for type 2 diabetes management - reflections from a diabetes care editors' expert forum. Diabetes Care. 2014;37(9):2647-2659.

24. Prasad-Reddy L, Isaacs D. A clinical review of GLP-1 receptor agonists: efficacy and safety in diabetes and beyond. Drugs Context. 2015;4:212283.

25. Vilsbøll T, Christensen M, Junker AE, Knop FK, Gluud LL. Effects of glucagon-like peptide-1 receptor agonists on weight loss: systematic review and meta-analyses of randomised controlled trials. BMJ. 2012;344:d7771.

26. Saunders C, Byrne CD, Guthrie B, et al. External validity of randomized controlled trials of glycaemic control and vascular disease: how representative are participants? Diabet Med. 2013;30(3):300-308.
Diabetes, Metabolic Syndrome and Obesity: Targets and Therapy is an international, peer-reviewed open-access journal committed to the rapid publication of the latest laboratory and clinical findings in the fields of diabetes, metabolic syndrome and obesity research. Original research, review, case reports, hypothesis formation, expert opinion and commentaries are all considered for publication. The manuscript management system is completely online and includes a very quick and fair peer-review system, which is all easy to use. Visit http://www.dovepress.com/testimonials.php to read real quotes from published authors. 